Original article

\title{
Proximate Predictors of Vaginal Delivery in Primigravid women at a Tertiary Health Facility in Ibadan, Nigeria.
}

\author{
Oluwasomidoyin O. Bello ${ }^{1 *}$, Chinedum A. Onebunne ${ }^{1}$, Raymond M.E Takpe ${ }^{1}$ \\ ${ }^{1}$ Obstetrics and Gynaecology Department, University College Hospital, Ibadan, Nigeria \\ *Corresponding author: Oluwasomidoyin O. Bello. Obstetrics and Gynaecology Department, \\ University College Hospital, Ibadan, Nigeria. Email:bellodoyin@yahoo.com
}

\begin{abstract}
\section{Background}

Successful vaginal delivery (VD) is the desire of every parturient. This is however not always so especially for primigravid women. Predictive factors can help the counselling process and allay the anxiety that this group of parturients experience.
\end{abstract}

\section{Objective}

To determine the prevalence and predictors of vaginal delivery among primigravid women at a tertiary health facility.

\section{Methods}

This was a 6-month cross-sectional study of 200 primigravid women that were planned for vaginal delivery. Information was obtained using structured proforma. Bivariate and multivariable analysis was used to identify the proximate predictors of VD.

\section{Results}

The prevalence of vaginal delivery was $50.0 \%$. Labour onset was spontaneous in $78.0 \% ; 10.0 \%$ had engaged fetal head prior to labour onset while labour was augmented in $18.0 \%$ of the parturients. Labour lasted $\leq 12$ hours in majority $(67.5 \%)$ with about half $(49.5 \%)$ having successful vaginal delivery. Factors predicting successful vaginal delivery were spontaneous labour onset $(\mathrm{OR}=3.555$, 95\% CI=1.626-7.774), booked pregnancy $(\mathrm{OR}=3.008,95 \% \mathrm{CI}=1.361-6.647)$, and early fetal head engagement $(\mathrm{OR}=6.484,95 \% \mathrm{CI}=1.686-24.943)$.

\section{Conclusion}

The identified predictive factors of vaginal delivery in this study will aid counselling of primigravid women regarding the likelihood of successful vaginal delivery especially in the absence of other obstetric complications.

Rwanda J Med Health Sci 2021;4(1):20-36

Keywords: vaginal delivery, primigravid parturient, labour onset. 


\section{Introduction}

Primigravidas are women who are pregnant for the first time. They are usually at risk due to lack of experience regarding childbearing. Primigravid women with unengaged fetal head at term are likely at increased risk of operative delivery.[1,2] The mode of delivery can be spontaneous vaginal delivery (SVD), instrumental vaginal delivery (IVD) or caesarean section (CS). SVD is a natural process that does not need significant medical intervention and it is often considered the preferred outcome for pregnancy.[3]

Meanwhile, instrumental VD involves the use of either forceps or a vacuum device to help the mother in achieving vaginal delivery of the fetus.[4] CS is a form of surgical intervention with delivery of the fetus through an incision made on the maternal abdomen and uterus with intention to avert or treat maternal or fetal life threatening complications. In most cases, when a vaginal delivery poses a risk on the life or health of either the mother or the baby, a CS or instrumental VD is performed.[5]

Globally, every year about 140 million women give birth. [6] In Nigeria, rates of spontaneous vaginal delivery among primigravidas range from $53.6 \%$ to $74.8 \% .[7,8]$ In labour management, it is essential to adopt and practice the accepted current guideline on the knowledge of the relevant screening and normal labour process. This will invariably increase the probability of having an uncomplicated VD and postpartum period as proposed by the American College of Obstetricians and Gynecologists.[9] Nevertheless, there are a few absolute contraindications to VD like major placenta previa and contracted pelvis. $[9,10]$ In addition, stress and pain were identified as issues bordering a normal delivery process.[11]

Primigravid women are in the category of obstetric high-risk patients because they are more predisposed to antenatal and intrapartum complications.[12,13] Likewise, studies have reported primigravid women have about 5 to 12 times higher risk of complications during labour and delivery.[12,13] Furthermore, primigravid women usually require more interventions in labour because of the need for more uterine force to overcome the inertia in the reproductive tract.[8] The uterus in primigravid women is noted to be less effective in maintaining uterine contractions thus augmentation of labour and instrumental deliveries are common among them. $[8,14,15]$ 
The concept of fetal head engagement $(2 / 5$ th of the fetal head or less palpable on abdominal examination) in primigravid women before the onset of labour increase the chance of VD.[8] Other documented factors predicting VD include normal range of maternal body mass index (BMI) and fetal birth weight.[8] Variations in these factors such as timing of fetal head engagement, high or low maternal body mass index and fetal birth weight have been identified as the underlying reasons for failure of labour progress, which is the main indication for CS among primigravidas.[8,16] Early booking, prompt referral at the onset of complications, antenatal risk assessment and health education during pregnancy were revealed to improve pregnancy outcome in primigravidas.[7]

When compared to vaginal delivery, CS has been shown to increase the prevalence of maternal morbidity and mortality.[16] CS is linked with several complications like an increased risk of uterine rupture, post-partum haemorrhage, damage to structures adjoining the uterus, endometritis, sepsis, placenta praevia in subsequent pregnancies, and ectopic pregnancy.[16] There is also evolving evidence that babies delivered through CS have different exposures to hormones and bacteria than babies delivered via the vagina and this may alter the development of the immune system.[17]

In Nigeria, there is aversion for CS for sociocultural, religious, and economic reasons.[7,18] Lawani et al. reported barriers to acceptance of CS is not inflenced by parity with some of the parturients studied insisting on VD despite counseling on the potential danger(s). [18] However, the study did not explore factors that predicts successful VD among women of different parity despite the fact that primigravidas and nulliparas are more likely to develop labour abnormalities that require intervention when compared with multiparous women.[8, 14, 15]

Identifying various factors that can predict or hinder VD among primigravidas will help in the counselling, education, and management of parturients in this category.

Therefore, it is against this background that this study aimed to determine the prevalence and predictors of successful vaginal delivery among primigravidas at the University College Hospital, Ibadan which could serve as a basis for counselling them during pregnancy and labour. 


\section{Methods}

\section{Study Design}

A cross-sectional study conducted between January 2017 and June 2017.

\section{Study location}

The study was conducted at the labour ward of the department of Obstetrics and Gynaecology of the University College Hospital, Ibadan, Oyo state, Nigeria. As a tertiary centre, the hospital serves as a referral centre for the primary and secondary health centres and private hospitals in Oyo state. University College Hospital Ibadan is the premier and the largest teaching hospital in Nigeria with an average of about 2,500 deliveries per year.

\section{Sampling Technique}

A purposive sampling strategy was used to recruit the primigravid women who met the inclusion criteria during the study period. The women were identified and informed about the study at presentation to labour ward or on the antenatal ward (for women scheduled for induction of labour). All the participants were counselled and recruited in labour ward after the vaginal examination performed was adjudicated to have met the inclusion criteria. The study population consist of primigravidas with singleton gestation at gestational age of 36 weeks and above. All the consenting primigravidas who presented at the labour ward with spontaneous labour or for induction of labour and are planned for VD were included in the study. Parturients who presented in advanced labour with cervical dilatation of greater than $3 \mathrm{~cm}$ and those that had previous history of uterine surgery were excluded from the study.

\section{Data collection tool and procedures}

At presentation in the labour ward, the parturient who met the inclusion criteria were reviewed and examined by the labour ward obstetrician or senior resident doctor (specialist trainees) to ascertain the eligibility for the study. The fetal head engagement and vaginal examination findings were documented.

An interviewer administered structured questionnaire adapted from previous studies on predictive factors and mode of delivery in primigravidas was used to obtain information from the study participants. [7,19] The questionnaire was pre-tested among 10 nulliparous women in the facility to assess for clarity and understanding of the questions and validation. It included three sections - Section 1 was the participant's demographic characteristics, obstetrics, and medical history. Section 2 was on the intrapartum events and Section 3 was the fetal and maternal outcomes. All needed information was extracted from the medical records within 24 hours of delivery. 
Two research assistants (nurses) trained on the objectives of the study, data collection tool and extraction of information from the medical records completed the proforma.

According to the labour ward protocol, admission CTG was performed on all the patients, uterine contraction monitored every 30 minutes if not on continuous CTG, fetal heart rate monitored every 30 minutes in the first stage and 5 minutes in the second stage of labour, vaginal examination was performed every 4 hours (or 2 hourly when necessary) during the first stage of labour and hourly in the second stage of labour. Labour was monitored on a partograph for all parturients. Augmentation of labour with oxytocin was commenced if uterine contractions were inadequate (less than 3 strong contractions in 10 minutes) and labour progress was poor. Labour is only augmented in the presence of the above conditions after other abnormalities such as cephalopelvic disproportion (CPD) and fetal distress have been excluded. The active phase of labour for those on induction of labour and spontaneous labour was managed the same way according to the standard protocol. Caesarean section was performed when indicated after a review by the senior obstetrician on duty.

\section{Data management and analysis}

Data collected was entered, cleaned and analyzed using the Statistical Package for the Social Sciences (SPSS) version 20. The dependent variable is the mode of delivery. The independent variables are booking status, BMI recorded at booking, onset of labour, augmentation of labour, early fetal head engagement $1<2 / 5$ th of the fetal head palpable per abdomen when cervical dilatation is $<3 \mathrm{~cm}$ ), gestational age at booking and at delivery. Continuous variables were described using mean \pm standard deviation (SD). Chi-square test was used to determine the association between the mode of delivery and the independent variables in categories.

Bivariate analysis was done to determine the relationship between the demographic and obstetric characteristics and mode of delivery. Logistic regression was used to establish the predictors of VD. The level of statistical significance was set at $\mathrm{p}<0.05$ and 95\% confidence level. The questionnaires were destroyed after successful entry and analysis. It was stored on a pass worded computer and there was also a back-up on an external storage. Only the principal investigator presently has access to it. 


\section{Ethical Considerations}

Ethical approval was obtained from the Institutional ethics review committee and a written informed consent was obtained from each of the parturient before administering the questionnaire. Anonymity was ensured by using identification numbers. No personal details or contact of the participants were obtained to ensure privacy. Confidentiality was established by maintaining strict non-disclosure of all the information obtained.

\section{Results}

During the study period, there was a total of 1,076 deliveries in labour ward of which 259 were primigravidas. Two hundred and six (206) primigravid women met

\section{Table 1. Demographic and Obstetrics Characteristics}

\begin{tabular}{lll}
\hline Variables & Frequency (n=200) & percent \\
\hline Age (years) & & \\
$15-24$ & 43 & 21.5 \\
$25-34$ & 137 & 68.5 \\
$\geq 35$ & 20 & 10.0 \\
Mean 28.15 (SD=4.78) & & \\
Booking status & 157 & \\
Booked & 43 & 78.5 \\
Unbooked & & 21.5 \\
Gestational age at booking & \\
(weeks)* & 155 & 98.7 \\
$\leq 14$ & 2 & 1.3 \\
$>14$ & & \\
Mean 16.76 (SD=10.3) & & \\
Gestational age at delivery & & \\
(weeks) & 50 & 25.0 \\
$36<37$ & 106 & 53.0 \\
$37-40$ & 44 & 22.0 \\
$>40$ & & \\
& &
\end{tabular}

the inclusion criteria and 200 consented to participate in the study.

\section{Demographic and Obstetrics characteristics}

The mean age was $28.15 \pm 4.78$ years with majority $(68.5 \%)$ in the 25-34 age category. Most of the women $(78.5 \%)$ were booked with mean gestational age at booking of $16.76 \pm 10.3$ weeks. Of the booked patients, $98.7 \%$ registered their pregnancy early at $\leq 14$ weeks. Fiftythree percent had term delivery and the mean gestational age at delivery of $38.62 \pm 2.32$ weeks. At booking, $49.0 \%$ were of normal body mass index (BMI) and $92.0 \%$ of them had no associated medical disorders (Table 1). 
Mean 38.62 (SD=2.32)

BMI*

Underweight (<19)

6

77

47

27
3.8

49.0

29.9

17.2

Obese (30 and above)

Associated medical

\section{disorder}

None

92.0

Hypertension

4

2.0

Gestational diabetes

Anaemia

1

0.5

2

1.0

Renal disease

1

0.5

Sickle cell disease

2

1.0

HIV

2

1.0

Hepatitis B infection

2

1.0

Fibroid in pregnancy

2

${ }^{*} \mathrm{n}=157 \quad$ **HIV- Human immunodeficiency virus infection; BMI-Body Mass Index

\section{Intrapartum events and outcomes}

Spontaneous onset of labour was observed in $78.0 \%$ of the study participants. Ninety percent had no fetal head engagement at presentation in labour ward and labour was augmented in only $18.0 \%$ of them. Labour (duration of active phase) lasted for $\leq 12$ hours in a higher proportion (67.5\%) with a mean duration of $7.36 \pm 1.1$ hours.
As regards the mode of delivery, $50.0 \%$ delivered via caesarean section and $49.5 \%$ had vaginal delivery. Only $0.5 \%$ had instrumental vaginal delivery (vacuum delivery). The proportion of live birth was high (98.0\%) and majority $(85.5 \%)$ of the babies had normal birth weight (Table 2). 
Table 2. Intrapartum events and outcomes

\begin{tabular}{|c|c|c|}
\hline Variables & Frequency & Percent \\
\hline \multicolumn{3}{|l|}{ Onset of labour } \\
\hline Spontaneous & 156 & 78.0 \\
\hline Induced & 44 & 22.0 \\
\hline \multicolumn{3}{|l|}{ Fetal head engagement } \\
\hline Engaged & 20 & 10.0 \\
\hline Not engaged & 180 & 90.0 \\
\hline \multicolumn{3}{|l|}{ Augmentation of labour } \\
\hline Yes & 36 & 18.0 \\
\hline No & 164 & 82.0 \\
\hline \multicolumn{3}{|l|}{ Duration of labour (hours) } \\
\hline$\leq 12$ & 135 & 67.5 \\
\hline$>12$ & 65 & 32.5 \\
\hline \multicolumn{3}{|l|}{ Mean 7.36(SD=1.1) } \\
\hline \multicolumn{3}{|l|}{ Mode of delivery } \\
\hline Vaginal Delivery & 99 & 49.5 \\
\hline Assisted Vaginal Delivery & 1 & 0.5 \\
\hline Caesarean Section & 100 & 50.0 \\
\hline \multicolumn{3}{|l|}{ Indications for Caesarean Section } \\
\hline Cephalopelvic disproportion & 36 & 36.0 \\
\hline Fetal distress & 31 & 31.0 \\
\hline Cervical dystocia & 18 & 18.0 \\
\hline Failure of descent & 11 & 11.0 \\
\hline Others & 4 & 4.0 \\
\hline complicatio & & \\
\hline \multicolumn{3}{|l|}{ postpartum } \\
\hline Yes & 17 & 8.5 \\
\hline No & 183 & 91.5 \\
\hline \multicolumn{3}{|l|}{ Fetal status } \\
\hline Live birth & 196 & 98.0 \\
\hline Still birth & 3 & 1.5 \\
\hline Early neonatal death & 1 & 0.5 \\
\hline \multicolumn{3}{|l|}{ Birth weight (kg) } \\
\hline Low Birth Weight (<2.5kg) & 29 & 14.5 \\
\hline $\begin{array}{l}\text { Normal Birth Weight }(2.5<4.0 \mathrm{~kg}) \\
\text { Mean birth weight } 2.99 \pm 0.58\end{array}$ & 171 & 85.5 \\
\hline
\end{tabular}




\section{Factors associated with vaginal delivery}

The factors associated with VD were their booking status $(p=0.025)$, onset of labour ( $p<0.001)$, fetal head engagement $\quad(p=0.002) \quad$ and gestational age at delivery $(p=0.039)$. Majority $(85.0 \%)$ of the women who booked had VD compared to $15.0 \%$ of those that were unbooked. A significant association exists between the women's booking status and having VD $(p=0.025)$. Eighty nine percent of the women who had spontaneous onset of labour had VD compared to $11.0 \%$ of those whose labour were induced. Onset of labour was significantly associated with having a VD $(\mathrm{p}<0.01)$.

VD occurred in $83.0 \%$ of the women whose fetal head were not engaged compared with $17.0 \%$ with early engaged fetal head with a significant difference of $\mathrm{p}=0.002$. Among the women who had VD, $62.0 \%$ delivered at term, 20.0\% delivered after 36 weeks but before 37 completed weeks and 18.0\% delivered post-term babies. A significant relationship exists between VD and the gestational age at delivery $(p=0.039)$, (Table 3$)$.

Table 3. Bivariate analysis of factors associated with vaginal delivery among primigravid women.

\begin{tabular}{|c|c|c|c|c|c|}
\hline \multirow{2}{*}{ Variable } & \multicolumn{2}{|c|}{ Mode of delivery } & \multirow{2}{*}{ Total } & \multirow{2}{*}{$\mathbf{X}^{2}$} & \multirow{2}{*}{ p-value } \\
\hline & $\begin{array}{l}\text { VD } \\
(n=100)\end{array}$ & $\begin{array}{l}\text { CS } \\
(n=100)\end{array}$ & & & \\
\hline Booking status & & & & 5.01 & 0.025 \\
\hline Booked & $85(85.0)$ & $72(72.0)$ & $157(78.5)$ & & \\
\hline Unbooked & $15(15.0)$ & $28(28.0)$ & $43(21.5)$ & & \\
\hline BMI $\left(\mathbf{k g} / \mathbf{m}^{2}\right)$ & & & & 1.62 & $0.655^{*}$ \\
\hline Underweight & $4(4.7)$ & $2(2.8)$ & $6(3.8)$ & & \\
\hline Normal weight & $39(45.9)$ & $38(52.8)$ & 77 (49.0) & & \\
\hline Overweight & $25(29.4)$ & $22(30.6)$ & 47 (29.9) & & \\
\hline Obese & $17(20.0)$ & $10(13.9)$ & $27(17.2)$ & & \\
\hline Associated medical disorder & & & & 1.09 & 0.297 \\
\hline Yes & $6(6.0)$ & $10(10.0)$ & $16(8.0)$ & & \\
\hline No & $94(94.0)$ & $90(90.0)$ & $184(92.0)$ & & \\
\hline Onset of labour & & & & 14.1 & $<0.001$ \\
\hline Spontaneous & $89(89.0)$ & $67(67.0)$ & $156(78.0)$ & & \\
\hline Induced & $11(11.0)$ & $33(33.0)$ & $44(22.0)$ & & \\
\hline Augmentation of labour & & & & 2.88 & 0.09 \\
\hline Yes & $26(24.5)$ & $10(11.9)$ & $36(18.0)$ & & \\
\hline No & $80(75.5)$ & $84(88.1)$ & $164(82.0)$ & & \\
\hline $\begin{array}{l}\text { Early Fetal head } \\
\text { engagement }\end{array}$ & & & & 10.89 & $0.002^{*}$ \\
\hline
\end{tabular}




\begin{tabular}{|c|c|c|c|c|c|}
\hline Engaged & $17(17.0)$ & $3(3.0)$ & $20(10.0)$ & & \\
\hline Not engaged & $83(83.0)$ & $97(97.0)$ & $180(90.0)$ & & \\
\hline Gestational age at delivery & & & & 6.51 & 0.039 \\
\hline $36<37$ weeks & $20(20.0)$ & $30(30.0)$ & $50(25.0)$ & & \\
\hline $37-40$ weeks & $62(62.0)$ & $44(44.0)$ & $106(53.0)$ & & \\
\hline >40 weeks & $18(18.0)$ & $26(26.0)$ & $44(22.0)$ & & \\
\hline Duration of labour (hours) & & & & 1.85 & 0.174 \\
\hline$\leq 12$ & $72(72.0)$ & $63(63.0)$ & $135(67.5)$ & & \\
\hline$>12$ & $28(28.0)$ & $37(37.0)$ & $65(32.5)$ & & \\
\hline Age (years) & & & & 0.222 & 0.637 \\
\hline$<35$ & $91(91.0)$ & $89(89.0)$ & $180(90.0)$ & & \\
\hline$\geq 35$ & $9(9.0)$ & $11(11.0)$ & $20(10.0)$ & & \\
\hline Fetal birth weight (kg) & & & & 1.01 & 0.315 \\
\hline Low birth weight $(<2.5)$ & $17(17.0)$ & $12(12.0)$ & $29(14.5)$ & & \\
\hline Normal birth weight $(2.5-4)$ & $83(83.0)$ & $88(88.0)$ & $171(85.5)$ & & \\
\hline
\end{tabular}

* $=$ fisher's exact BMI - Body mass index

\section{Predictors of vaginal delivery}

In the multivariable analysis, the predictors of VD were booking status, onset of labour and fetal head engagement. Booked primigravidas were three times more likely than unbooked primigravidas to have VD (OR=3.008, 95\%CI=1.361-6.647).
Also, those who experienced spontaneous onset of labour were four times more likely to have VD than those whose labour were induced $(\mathrm{OR}=3.555,95 \% \mathrm{CI}=1.626$ 7.774) while those with early engaged fetal head were seven times more likely to have VD compared with those with unengaged fetal head $(\mathrm{OR}=6.484,95 \% \mathrm{CI}=1.686$ 24.943), (Table 4). 
Table 4. Predictors of vaginal delivery

\begin{tabular}{llll}
\hline Factors & $\begin{array}{l}\text { ODDS } \\
\text { RATIO }\end{array}$ & 95\% CI & P-Value \\
\hline Booking status & & & \\
Booked & 3.008 & $1.361-6.647$ & 0.006 \\
Unbooked & 1 & - & \\
Onset of labour & & & \\
Spontaneous & 3.555 & $1.626-7.774$ & 0.001 \\
Induced & 1 & - & \\
Fetal head engagement & & & \\
Engaged & 6.484 & $1.686-24.943$ & 0.007 \\
Not engaged & 1 & - & \\
Gestational age at delivery & & & \\
(weeks) & & & 0.981 \\
$36<37$ & 1.011 & $0.417-2.452$ & \\
$38-40$ & 1.786 & $0.830-3.842$ & 0.138 \\
$>40$ & 1 & & \\
\hline
\end{tabular}

\section{Discussion}

This study revealed the prevalence and predictors of vaginal delivery among primigravidas. The findings revealed that spontaneous labour onset, booking status and early fetal head engagement in the absence of other obstetric complications are predictive factors of vaginal delivery in primigravid women.

\section{Demographic and Obstetrics characteristics}

The proportion of primigravid parturients out of the 1,076 deliveries within the study period was $23.7 \%$. This value falls within the range of values $(15.3 \%$ to $45.6 \%$ ) from studies in different regions in Nigeria.[8,19,20] In this study, majority (78.5\%) of the pregnancies were booked. This is similar to the findings of Okunade et al in Southwestern region in which $76.7 \%$ of the primigravidas studied booked their pregnancy.[19] However, some Nigerian studies reported a higher proportion unbooked or 'latebooked' pregnancies.[8,21,22] Majority of the booked parturients 
had a successful VD compared to the unbooked parturients which was statistically significant. Some studies have also reported poor pregnancy outcomes among women with late booking and those unbooked for antenatal care. $[19,21]$

The mean age of the study participants of $28.15 \pm 4.78$ years is similar to those reported in Southwestern Nigeria and Denmark, but age was not a predictive factor for vaginal delivery.[8,17] However, elderly primigravidas (aged 35 or more) were found to have lower rate of VD which is similar to the findings of Moses et al.[23] This may be related to the fact that they are at high risk of several medical and obstetrics complications.[20]

Meanwhile, the prevalence of successful vaginal delivery among the primigravidas was $50.0 \%$ essentially equal to the caesarean delivery rate which disagrees with reports from other studies in which higher proportion of the primigravidas had VD. $[8,24,25]$ This could be because of the use of electronic fetal monitoring cardiotocograph (CTG) in the study centre. Studies have shown increase in CS rate due to nonreassuring fetal heart rate tracing in health institutions where CTG is used to monitor parturient in labour.[26,27] This corroborates with our finding of fetal distress as one of the main indications for CS.
The major indications for CS were failure to progress due to cephalopelvic disproportion and fetal distress. This agrees with the finding from other studies that identified similar indications as leading reasons for caesarean section among primigravid women. $[8,28]$ In the primigravida, the uterus is likely less efficient physiologically and this may cause irregular contractions with slow progress in labour leading to fetal distress and failure to progress in labour.[15]

Labour lasted for $\leq 12$ hours in more than half of the parturient and only $18.0 \%$ of those with spontaneous laboured augmentation. This was consistent with studies by Khurshid et al. and Chaudhary et al. who reported a similar pattern as regards the duration of labour.[24,29] Lower rate of labour augmentation was however found in some other studies.[1,25,30]

\section{Predictors of Vaginal delivery in Primigravid women}

The predictors of VD identified were labour onset, booking status and fetal head engagement. Primigravidas with spontaneous onset of labour were more likely to have VD compared to those with induced labour $(89.0 \%$ versus $11.0 \%$ and was statistically significant. Those with spontaneous onset of labour were four times more likely to have vaginal delivery than those with induced labour. This is in keeping 
with other studies in which spontaneous onset of labour was a predictor of successful vaginal birth.[30-32]

Booked primigravidas were three times more likely to have VD compared with their unbooked counterparts which buttresses findings.[33] This may be because the booked patients have more advantages regarding identification of contraindication to VD and risk factors for unsuccessful VD for which the patient would have been offered an elective CS. Also, the booked patients receive counselling on birth preparedness and complication readiness during the antenatal visit making them more emotionally and psychologically prepared for labour and delivery compared to their unbooked counterparts. Early fetal head engagement was also observed to be a factor predicting VD among the parturients as those with engaged fetal head at presentation were seven times more likely to have VD compared with those with an unengaged fetal head. This agrees with other studies which reported women with early labour fetal head engagement were more likely to achieve VD than those with persistently unengaged fetal head at advanced cervical dilatation.[8,31,34] Engaged fetal head results in good contact between the fetal head and the cervix, thus reducing the risk of dystocia.[35] Once engagement occurs, it is an indication that the pelvic inlet is adequate for the fetal head and vaginal delivery becomes more likely.

\section{Limitations}

The main limitation is that all the factors (including epidural analgesia, social support) that may influence labour outcome could not be accounted for, though many identifiable confounders were controlled for using multivariable analysis. Despite all these, our findings identified the proximate predictors of VD among primigravidas. This is crucial in modern obstetric care where women ought to experience institutional routine care grounded on evidence-based medicine.

\section{Conclusion}

Proximate predictors of vaginal delivery among the studied primigravid women were booking status, fetal head engagement and spontaneous onset of labour and the prevalence of vaginal delivery was $50.0 \%$. High rate of caesarean delivery in the primigravid women could have a cascading effect on their reproductive career. Therefore, this calls for adequate counselling of these women, labour management according to guideline or protocol and prompt intervention by skilled health care personnel considering the identified predictive factors of vaginal delivery.

\section{Conflict of interest}

All authors declare no conflict of interest. 


\section{Authors' contribution}

O.O Bello - OOB, R.M.E Takpe RMET, C.A Onebunne - CAO

OOB: Design of the study, data acquisition, analysis and interpretation, drafted the manuscript and substantively revised it.

RMET: Design of the study, Data acquisition, analysis and interpretation, and substantively revised the manuscript.

CAO: Data acquisition, drafted the manuscript and substantively revised the manuscript.

All authors approved the manuscript in the present format.

This article is published open access under the Creative Commons Attribution-NonCommercial NoDerivatives (CC BYNC-ND4.0). People can copy and redistribute the article only for noncommercial purposes and as long as they give appropriate credit to the authors. They cannot distribute any modified material obtained by remixing, transforming or building upon this article. See https://creativecommons.org/licenses / by-ncnd/4.0/

\section{Reference}

1. Sudhir S, Mishra S. The outcome of labour in primigravida with term gestation and unengaged head at onset of labour. Indian $J$ Obstet Gynecol Res. 2016;3:199-202.

2. Raksha G., Anjali T. KT. An Exploratory Study to Assess the Factors Causing Anxiety among Primigravida Planned for Normal Vaginal Delivery and Caesarean Section Admitted at Mata Kaushalya Hospital, Patiala, Punjab. Matern Pediatr Nutr. 2017;03:1-8.

3. Tenaw Z, Kassa ZY, Kassahun G AA. Maternal Preference, Mode of Delivery and Associated Factors among Women Who Gave Birth at Public and Private Hospitals in Hawassa City, Southern Ethiopia. Ann Glob Heal. 2019;85:1-7.

4. Patterson DA, Winslow M MC. Spontaneous Vaginal Delivery. Am Fam Physician 2008;78:336-41, 343-4. Available from: http://www.aafp.org/afp

5. Akinola OI, Fabamwo AO, Tayo AO, Rabiu KA, Oshodi YA, Alokha ME. Caesarean section - an appraisal of some predictive factors in Lagos Nigeria. BMC Pregnancy Childbirth. 2014;14:217.

6. World Health Organization. Sexul and Reproductive health - Making childbirth a positive experience. February, 2018. Available from:

https: / /www.who.int/reprod uctivehealth/intrapartumcare/en/ 
7. Ojiyi E, Anozie U, Dike E, Okeudo C, Anolue F, Uzoma O, et al. Pregnancy Outcome In Primigravidae In A Tertiary Hospital: A Three-Year Review. Internet $J$ Gynecol Obstet. 2012;16:1-5.

8. Adeyemi A, Adekanle D, Afolabi A. Predictors of vaginal delivery in nulliparous mothers. Ann Afr Med. 2014;13:35-40.

9. American College of Obstetricians and Gynecologists. Vaginal birth after previous cesarean delivery. Obstet Gynecol. 2010;116:450-63.

10. American College of Obstetricians and Gynecologists. Scheduled cesarean delivery and the prevention of vertical transmission of HIV infection. Int $J$ Gynecol Obstet. 2001;73:279-81.

11. Khamehchian M, AdibHajbaghery M, Heydarikhayat N, Rezaei M, Sabery M. Primiparous women's experiences of normal vaginal delivery in Iran: A qualitative study. BMC Pregnancy Childbirth. 2020;20:1-8.

12. Hoque $M$. Incidence of Obstetric and Foetal
Complications during Labor and Delivery at a Community Health Centre, Midwives Obstetric Unit of Durban, South Africa. ISRN Obstet Gynecol. 2011;2011:1-6.

13. Hashim N, Naqvi S, Khanam M, Jafry HF. Primiparity as an intrapartum obstetric risk factor. $J$ Pak Med Assoc. 2012;62:694-8.

14. Adaji SE, Shittu SO, Sule ST. Operative vaginal deliveries in Zaria, Nigeria. Ann Afr Med. 2009;8:95-9.

15. Shields SG, Ratcliffe SD, Fontaine P, Leeman L. Dystocia in nulliparous women. Am Fam Physician. 2007;75:1671-8.

16. Zandvakili F, Rezaie M, Shahoei R, Roshani D. Maternal outcomes associated with caesarean versus vaginal delivery. J Clin Diagnostic Res. 2017;11:QC01-4.

17. Wise J. Alarming global rise in caesarean births, figures show. BMJ. 2018. p. k4319.

18. Lawani LO, Igboke FN, Ukaegbe CI, Anozie OB, Onu FA, Agbata TA, et al. Perception and socio-cultural barriers to the acceptance of caesarean delivery in a tertiary hospital in Abakaliki, 
South East Nigeria. Int $J$ Women's Heal Reprod Sci. 2019;7:163-8.

19. Okunade $\mathrm{K}$, Okunola $\mathrm{H}$, Oyeneyin L, Habeeb-Adeyemi F. Cross-sectional study on the obstetric performance of primigravidae in a teaching hospital in Lagos, Nigeria. Niger. Med. J. 2016. p. 303.

20. Shehadeh A. Elderly Primigravida and Pregnancy Outcome. JRMS Dec. 2002;9:8-11.

21. National Population Commission (NPC) [Nigeria], ICF 2019. Nigeria Demographic Health Survey 2018. Abuja, Nigeria, and Rockville, Maryland, USA: NPC and ICF.; 2019.

22. Oladokun A, Oladokun RE, Morhason-Bello I, Bello AF AB. Proximate predictors of early antenatal registration among Nigerian pregnant women. Ann Afr Med. 2010. p. 222-5.

23. Moses V, Dalal N. Pregnancy outcome in elderly primi gravidas. Int $\mathrm{J}$ Reprod Contraception, Obstet Gynecol. Medip Academy; 2016;3731-5.
24. Khurshid N, Sadiq F. Management of primigravida with unengaged head at term. Pakistan J Med Heal Sci. 2012;6:36-8.

25. E1 Nassery NS, Kattan EA E1, Fouad MA, Affifi TM. Unengaged Head in Primigravidas, Will it Affect the Chance of Having a Vaginal Birth? Imstrlnt". Med $\mathrm{J}$ Cairo Univ [Internet]. 2013;81:221-5. Available from:

www.medicaljournalofcairou niversity.com

26. Chetandas P, Zahiruddin S, Jabeen N, Baloch R, Shaikh $F$. Increasing rate of Caesarean Section Due to Non-Reassuring Cardiotocography. Open $J$ Obstet Gynecol. 2017;07:351-7.

27. Alfirevic $Z$, Devane D, Gyte GML CA. Continuous cardiotocography (CTG) as a form of electronic fetal monitoring (EFM) for fetal assessment during labour. In: The Cochrane Collaboration, editor. Cochrane Database Syst Rev. John Wiley \& Sons, Ltd; 2017. p. 1-141.

28. Ahmed S, Alsheeha M, Alsammani M. Risks and indications for cesarean sections in primiparous 
women: A case-control study. Ann Trop Med Public Heal. 2013;6:541-4.

29. Chaudhary S, Farrukh R, Dar A, Humayun S. Outcome of labour in nullipara at term with unengaged vertex. $J$. Ayub Med. Coll. Abbottabad. 2009. p. 131-4.

30. Unnisa S, M.S P. Unengaged head at term in primigravida: does it affect the chance of having a normal delivery? Int $J$ Reprod Contraception, Obstet Gynecol. 2019;8:1616.

31. Iqbal S, Sumaira S. Outcome of primigravida with unengaged versus engaged fetal head at term of onset or labour. Biomedica. WC; 2009;25:159-62.

32. Sonawane PK. Comparative study between unengaged and engaged fetal head in primigravida at term or in labour. Int $J$ Reprod Contraception, Obstet Gynecol. 2018;7:4569.
33. Olayemi O, Odukogbe AA, Omigbodun AO AA. Effect of caesarean section on the perinatal outcome in singleton breech deliveries in Ibadan. Niger $J$ Clin Pract. 2002;5:41-4.

34. Ambwani B. Primigravidas With Floating Head At Term Or Onset Of Labor. Internet $J$ Gynecol Obstet. 2003;3:4-7.

35. Kjærgaard H, Olsen J, Ottesen B, Nyberg P, Dykes AK. Obstetric risk indicators for labour dystocia in nulliparous women: A multicentre cohort study. BMC Pregnancy Childbirth. 2008;8:1-8. 